\title{
EFFECTS OF MULTIVITAMIN SUPPLEMENTATION ON HEART RATE RESPONSE IN AEROBICALLY UNTRAINED COLLEGE AGED STUDENTS
}

\author{
G. Ryan1, C. Katica1, S. Bishop1, R. Herron1, A. Bosak2, and M. Sloniger, FACSM3 \\ 1Dept. of Kinesiology, University of Alabama, 2Dept. of Health and Human \\ Performance, Georgia Southwestern State University, 3Dept. of Health and Phys. Ed., \\ Indiana University of Pennsylvania.
}

Multivitamin use is increasingly prevalent in the US among most every population. Yet, previous research noted no performance benefits among individuals following a supplementation period. This study focused on the potential physiological benefits from a three week multivitamin supplementation period using 24 (20.9 $\pm 2.6 \mathrm{yr})$ aerobically untrained college aged students. Subjects were divided equally into three groups (placebo $=\mathrm{PL}$, multivitamin $=\mathrm{MV}$, control $=\mathrm{CL}$ ) and asked to perform separate eight minute bouts of exercise, consisting of six min of moderate (60\% VO2max) intensity followed immediately by two min of high ( $85 \% \mathrm{VO} 2 \mathrm{max})$ intensity exercise on a cycle ergometer. Following the supplementation period, participants came back and performed the same exercise bout. Heart rates were measured with a POLAR Heart Rate monitor and recorded every two min. Data analysis, using ANOVA comparing the three groups, indicated a statistically significant HR interaction. Post hoc paired t-tests, comparing the pre/post supplementation tests of all groups, noted significant differences in HR between MV group during the $60 \% \mathrm{VO} 2(\mathrm{p}=0.04)$ intensity bout, and approached significance at $85 \% \mathrm{VO} 2(\mathrm{p}=0.10)$. No difference occurred for the CL group during either moderate or high intensity exercise. The results indicate that the introduction of a supplement, whether real or placebo, may have a physiological effect on the heart rate of aerobically untrained college students. 